\title{
BMJ Open Detection of cancers and advanced adenomas in asymptomatic participants in colorectal cancer screening: a cross- sectional study
}

\author{
Anna Lisa Schult (D) , ${ }^{1,2,3}$ Edoardo Botteri, ${ }^{1,4}$ Geir Hoff, ${ }^{1,2,5}$ Kristin R Randel, ${ }^{1,5,6}$ \\ Eirin Dalén, ${ }^{7}$ Sigrun Losada Eskeland, ${ }^{3}$ Øyvind Holme, ${ }^{1,6,8}$ \\ Thomas de Lange (i) ${ }^{9,10,11}$
}

To cite: Schult AL, Botteri E, Hoff G, et al. Detection of cancers and advanced adenomas in asymptomatic participants in colorectal cancer screening: a crosssectional study. BMJ Open 2021;11:e048183. doi:10.1136/ bmjopen-2020-048183

- Prepublication history and additional supplemental material for this paper are available online. To view these files, please visit the journal online. To view these files, please visit the journal online (http://dx.doi. org/10.1136/bmjopen-2020048183).

Received 22 December 2020 Accepted 18 June 2021

Check for updates

(c) Author(s) (or their employer(s)) 2021. Re-use permitted under CC BY-NC. No commercial re-use. See rights and permissions. Published by BMJ.

For numbered affiliations see end of article.

Correspondence to

Dr Anna Lisa Schult;

anna.schult@kreftregisteret.no

\section{ABSTRACT}

Objectives To assess detection rates for colorectal cancer (CRC) and advanced adenomas in asymptomatic CRC screening participants and bowel symptoms in association with CRC and advanced adenoma.

Design Cross-sectional study.

Setting Two screening centres.

Participants 42554 men and women, aged 50-74 years, participating in a randomised CRC screening trial. 36059 participants underwent a sigmoidoscopy (and follow-up colonoscopy if positive sigmoidoscopy) and 6495 underwent a colonoscopy after a positive faecal immunochemical test (FIT).

Primary and secondary outcome measures Proportion of asymptomatic participants diagnosed with CRC or advanced adenomas. Prevalence of bowel symptoms (rectal bleeding, change in bowel habits, diarrhoea, constipation, bloating, alternating bowel habits, general symptoms, other bowel symptoms) recorded by the endoscopist and their association with CRC and advanced adenomas.

Results Among sigmoidoscopy participants, 7336 $(20.3 \%)$ reported at least one symptom. $120(60 \%)$ out of 200 individuals with screen-detected CRC and 1301 $(76.5 \%)$ out of 1700 with advanced adenoma were asymptomatic. Rectal bleeding was associated with detection of CRC and advanced adenoma (OR 4.3, 95\% Cl 3.1 to 6.1 and $1.8,95 \% \mathrm{Cl} 1.5$ to 2.1 , respectively), while change in bowel habits only with CRC detection (OR 3.8, 95\% Cl 2.4 to 6.1). Among the FIT positives, $2173(33.5 \%)$ reported at least one symptom. Out of 299 individuals with screen-detected CRC and 1639 with advanced adenoma, 167 (55.9\%) and 1175 (71.7\%) were asymptomatic, respectively. Detection of CRC was associated with rectal bleeding (OR 1.8, 95\% $\mathrm{Cl} 1.4$ to 2.3), change in bowel habits (OR $2.2,95 \% \mathrm{Cl} 1.4$ to 3.5 ) and abdominal pain (OR 1.8, 95\% $\mathrm{Cl} 1.2$ to 2.7$)$.

Conclusions Some bowel symptoms increased the likelihood of being diagnosed with CRC or advanced adenoma. However, the majority of individuals with these findings were asymptomatic. Asymptomatic individuals should be encouraged to participate in CRC screening. Trial registration number Clinicaltrials.gov Identifier: NCT01538550.

\section{Strengths and limitations of this study}

- This is so far the largest study assessing the proportion of asymptomatic patients diagnosed with colorectal cancer and advanced adenoma in a screening population.

- Its size, high participation rate and prospective recording of symptoms support the validity of the study results.

- The results may not be generalisable to the general public, but may be transferred to comparable screening populations.

\section{INTRODUCTION}

Colorectal cancer (CRC) is the second most deadly and the third most commonly diagnosed cancer in the world. ${ }^{1}$ Bowel symptoms occur late in the course of the illness ${ }^{2}$ and may frequently be misinterpreted as caused by benign conditions. ${ }^{3-5}$ Therefore, CRC is often detected at an advanced stage beyond prospects of cure or at the cost of a burdensome and expensive treatment. ${ }^{6}$ Increasing incidence and the fact that early detection and treatment of colorectal neoplasia is feasible and improves prognosis has led to worldwide screening initiatives. CRC is mainly caused by slow progression from precancerous lesions, such as adenomas. Advanced adenomas are the direct precursor lesions of $\mathrm{CRC},{ }^{7}$ possible to remove endoscopically to prevent CRC.

Depending on the test, CRC screening can detect precursors or act through detection of early-stage cancer. Traditionally, endoscopic screening (sigmoidoscopy and colonoscopy) has been considered preventive while faecal occult blood testing (FOBT) has been considered to act mainly through early detection. ${ }^{8}$ There are two types of FOBT. Qualitative guaiac-based tests are not specific for human haemoglobin, and therefore 
particularly prone to ingested food items causing false positive test results, while faecal immunochemical tests (FITs) can be qualitative or quantitative and detect specifically human globin using antibodies without need for dietary restrictions. Quantitative FITs are the most widely used FOBTs today, they have better sensitivity for CRC and advanced adenomas than the guaiac-based FOBT and may also be preventive. ${ }^{10}$

High compliance to recommended CRC screening is crucial for the effectiveness of the programme. Individuals not suffering from bowel symptoms have a lower adherence rate to screening programmes, ${ }^{11-14}$ while the presence of symptoms triggers a positive attitude towards screening ${ }^{15}$ associated with high adherence according to a review based on 44 US studies. ${ }^{16}$ Several trials have shown a high prevalence of bowel symptoms in screening populations even if the purpose of screening is primarily to identify neoplasia in asymptomatic individuals. In an Italian sigmoidoscopy screening trial, $35 \%$ of the participants reported bowel symptoms. ${ }^{17}$ In FOBT positive screening populations, the prevalence of bowel symptoms is reported to be between $47 \%$ and $78 \% .^{18-21}$

Systematic reviews and meta-analyses provide evidence for an association between rectal bleeding and CRC in primary and secondary care, ${ }^{3422}$ while other 'alarm symptoms' such as change in bowel habits, abdominal pain and bloating have uncertain diagnostic value. ${ }^{523}$ The usefulness of symptoms in predicting CRC or advanced adenomas in screening populations is contradictory. ${ }^{17-21}$ In addition, there is limited attention on the detection rates among truly asymptomatic individuals in these screening populations.

The aim of this study was to assess the proportion of truly asymptomatic individuals diagnosed with CRC or advanced adenoma in participants in a large randomised population-based Norwegian CRC screening trial. A secondary aim was to explore the prevalence, type of symptoms and their association with endoscopically detected CRC and advanced adenoma.

\section{METHODS}

\section{Design and participation}

The current cross-sectional study was performed as part of a Norwegian population-based, randomised CRC screening trial comparing the effectiveness of two screening modalities. The trial is described in detail elsewhere. ${ }^{24}$ Briefly, all men and women, aged 50-74 years and living in one of two areas in South East Norway, were drawn directly from the population registry and randomised in 2012 without preconsent 1:1 to be invited to screening by either once-only sigmoidoscopy or biennial FIT for up to four rounds. An information leaflet including general information about CRC, the screening methods, and risks and benefits of screening was sent together with the invitation. Invitees were informed that early-stage CRC is mostly asymptomatic, but no information was provided on what to do if bowel symptoms were present. In the sigmoidoscopy group, $52 \%$ of all invited individuals participated, while $68 \%$ of individuals invited to FIT screening participated in at least one FIT round. In the present cross-sectional study, we included all participants attending primary sigmoidoscopy screening (sigmoidoscopy group) and all participants attending colonoscopy after a positive FIT (FIT group) invited between March 2012 and May 2019. The endoscopies were performed at two screening centres.

In the sigmoidoscopy group, attenders provided written informed consent on attendance, while in the FIT group, the return of a faecal sample was considered as consent.

\section{Patient and public involvement}

A user representative was one of the members of the Norwegian bowel cancer screening trial's steering committee involved in the design, management and conduct of the screening trial. The results of the present study will be made publicly available on the homepage of the Cancer Registry of Norway (https://www.kreftregisteret.no/en/).

\section{Symptoms}

On attendance, just prior to the endoscopic examination, all individuals were asked about their medical history, including bowel symptoms. The following symptoms and their duration were registered; rectal bleeding (visible blood in stools), change in bowel habits (a change from what is normal for the participant), diarrhoea, constipation, bloating, alternating bowel habits (generally varying bowel habits), general symptoms and other symptoms. The duration of symptoms was recorded in number of months up to 24 months and 'more than 24 months'. We defined recent symptoms as symptoms lasting for up to 6 months while longer lasting symptoms were considered persistent.

\section{Sigmoidocopy}

Enema administered on attendance at the screening centre was used for bowel cleansing. The Olympus Exera II/III systems were used for sigmoidoscopies and follow-up colonoscopies (Olympus Europa, Hamburg, Germany). The colonoscope was inserted as far as possible according to a predefined time slot, or until a lesion $\geq 10 \mathrm{~mm}$ was detected, or limitations in bowel preparation or the persons discomfort did not permit further progress. ${ }^{24}$ The criteria for referral for follow-up colonoscopy were detection of CRC, any polyp $\geq 1 \mathrm{~cm}$, three or more adenomas and any adenoma with high-grade dysplasia or $\geq 25 \%$ villous architecture.

\section{Faecal immunochemical test}

The OC-Sensor Diana (Eiken Chemical, Tokyo, Japan) was used for FIT analysis at a single laboratory at Oslo University Hospital. The threshold defining a positive test was $15 \mu \mathrm{g}$ haemoglobin/g faeces. Individuals with a positive FIT were scheduled for a follow-up colonoscopy within 4 weeks. 


\section{Outcome measures}

CRC was defined as adenocarcinoma of the rectum or colon. Advanced adenoma was defined as adenoma $\geq 1 \mathrm{~cm}$, or an adenoma with $\geq 25 \%$ villous histology or high-grade dysplasia, sessile serrated class lesions were not included. For participants with multiple findings, the most advanced lesion was counted. In sigmoidoscopy participants, the most advanced neoplasia could be detected either at sigmoidoscopy or at follow-up colonoscopy.

\section{Statistics}

$\chi^{2}$ test, non-parametric Fisher test and non-parametric Cuzick test for trend ${ }^{25}$ were used, as appropriate, to assess the association between symptoms and outcomes: CRC and advanced adenoma. Multivariable logistic regression analyses were used to estimate OR with $95 \%$ CI. Age and sex were included in all multivariable models, and we also performed multivariable logistic regression stratified by sex. We did not include general symptoms, alternating bowel habits or other symptoms in the multivariable models, since they were poorly defined and their inclusion did not cause any significant changes in the estimates. If patients reported any of these three symptoms, they were categorised as having one symptom when the number of symptoms was assessed.

We tested multicollinearity by calculating the variance inflation factors, and it was considered negligible.

Statistical analyses were performed using SAS software V.9.4 (SAS Institute) and Stata statistical software V.16.1 (StataCorp, College Station, Texas, USA).

\section{RESULTS}

In total, 42554 individuals were included in the present study, 36059 sigmoidoscopy participants, and 6495 FIT positive participants. In the sigmoidoscopy group, 3297 $(9.1 \%)$ underwent follow-up colonoscopy. The characteristics of the included individuals are shown in table 1.

\section{Sigmoidoscopy group}

At least one bowel symptom was reported by 7336 sigmoidoscopy participants (20.3\%): 2456 (6.8\%) individuals reported rectal bleeding; the following symptoms compatible with irritable bowel syndrome were reported by 1358 (3.8\%) abdominal pain, $1003(2.8 \%)$ change in bowel habits, $1114(3.1 \%)$ constipation, 1017 (2.8\%) bloating and 691 (1.9\%) diarrhoea (table 2). In addition, 2360 individuals $(6.5 \%)$ reported alternating bowel habit and/ or general symptoms and/or other symptoms.

In total, 200 individuals $(0.6 \%)$ were diagnosed with CRC and 1700 (4.7\%) with at least one advanced adenoma; of whom $120(60 \%)$ individuals with CRC and 1301 (76.5\%) with advanced adenoma were asymptomatic.

At unadjusted analysis, we found that the detection of CRC was associated with rectal bleeding, changes in bowel habits and diarrhoea. Rectal bleeding was associated with the detection of advanced adenoma (table 2).

At multivariable analysis, rectal bleeding (OR 4.3, 95\% CI 3.1 to 6.1 ), change in bowel habits (OR 3.8, 95\% CI 2.4 to 6.1 ) and diarrhoea in men (OR 3.1, 95\% CI 1.4 to 6.9) were associated with the detection of CRC (table 2 and figure 1). The positive predictive value (PPV) was $1.9 \%$ for rectal bleeding and $2.2 \%$ for changes in bowel habits (online supplemental table 1). Individuals with recent rectal bleeding had higher ORs of having a CRC (OR 10.2, 95\% CI 5.8 to 17.6) than those with persistent symptoms (OR 3.3, 95\% CI 2.2 to 5.0) compared with those not reporting rectal bleeding (online supplemental table 2). Advanced adenomas were associated with rectal bleeding in both sexes and diarrhoea in men (ORs 1.8, $95 \%$ CI 1.5 to 2.1 and $1.6,95 \%$ CI 1.0 to 2.4 , respectively). Finally, an increasing number of symptoms was associated with an increasing detection rate of CRC and advanced adenomas both at unadjusted (table 2) and multivariable analysis (ORs 1.8, 95\% CI 1.5 to 2.1 and ORs 1.1, 95\% CI 1.1 to 1.2 , respectively).

\section{FIT group}

A total of $2173(33.5 \%)$ participants reported at least one bowel symptom: 1198 (18.4\%) individuals reported rectal bleeding; $343(5.3 \%)$ abdominal pain, $260(4.0 \%)$ change in bowel habits, $280(4.3 \%)$ constipation, 158 $(2.4 \%)$ bloating and $168(2.6 \%)$ diarrhoea (table 2$)$.

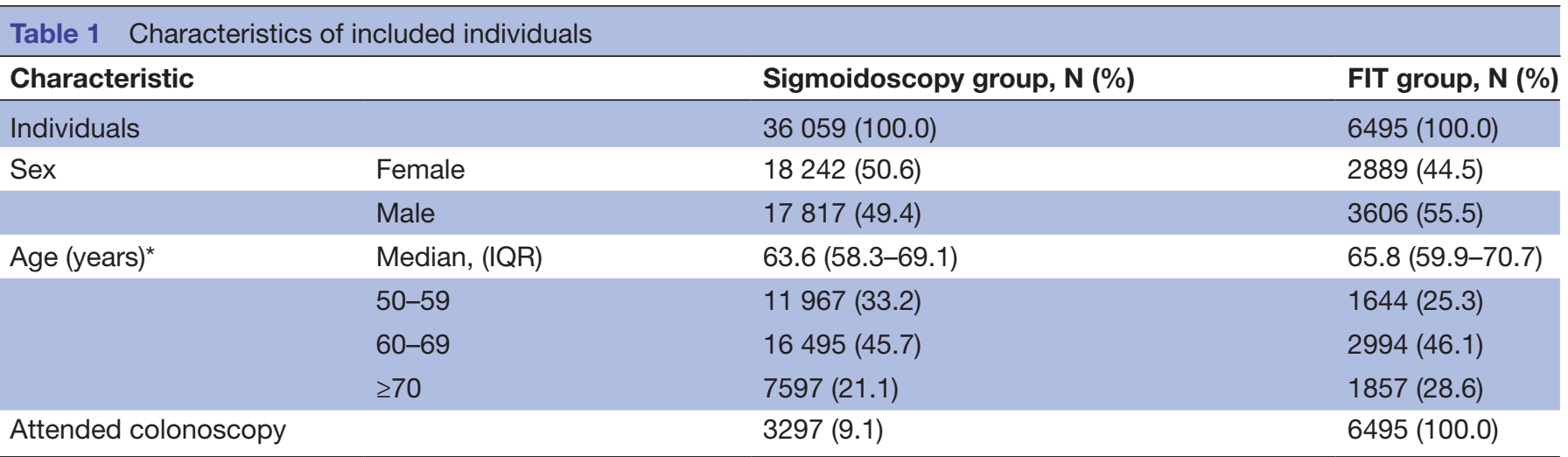

*Age at invitation to sigmoidoscopy resp. at invitation to the FIT test that was followed by colonoscopy.

.FIT, faecal immunochemical test; IQR, interquartile range. 
Table 2 Unadjusted analysis of the association between bowel symptoms and the detection of colorectal cancer or advanced adenoma

\begin{tabular}{|c|c|c|c|c|c|c|}
\hline & \multicolumn{3}{|c|}{ Sigmoidoscopy group } & \multicolumn{3}{|l|}{ FIT group } \\
\hline & $\begin{array}{l}\text { Participants } \\
\text { (col \%) }\end{array}$ & CRC (row \%) & $\begin{array}{l}\text { Advanced } \\
\text { adenoma * } \\
\text { (row \%) }\end{array}$ & Participants (col \%) & CRC (row \%) & $\begin{array}{l}\text { Advanced } \\
\text { adenoma* } \\
\text { (row \%) }\end{array}$ \\
\hline Abdominal pain & & & & & $\ddagger$ & $\S$ \\
\hline Absence & 34701 (96.2) & $195(0.6)$ & $1642(4.8)$ & $6152(94.7)$ & $272(4.4)$ & $1573(26.8)$ \\
\hline Presence & $1358(3.8)$ & $5(0.4)$ & $58(4.3)$ & $343(5.3)$ & $27(7.9)$ & $66(20.9)$ \\
\hline \multicolumn{7}{|l|}{ Bloating } \\
\hline Absence & 35042 (97.2) & $195(0.6)$ & $1665(4.8)$ & $6337(97.6)$ & $293(4.6)$ & $1603(26.5)$ \\
\hline Presence & $1017(2.8)$ & $5(0.5)$ & $45(4.5)$ & $158(2.4)$ & $6(3.8)$ & $36(23.7)$ \\
\hline Change in bowel habits & & ๆ & & & १ & \\
\hline Absence & 35056 (97.2) & $178(0.5)$ & $1647(4.7)$ & $6235(96.0)$ & $274(4.4)$ & $1585(26.6)$ \\
\hline Presence & $1003(2.8)$ & $22(2.2)$ & $53(5.4)$ & $260(4.0)$ & $25(9.6)$ & $54(23.0)$ \\
\hline Constipation & & & $\S$ & & & $\S$ \\
\hline Absence & 34945 (96.9) & $194(0.6)$ & $1662(4.8)$ & $6215(95.7)$ & $289(4.7)$ & $1585(26.8)$ \\
\hline Presence & $1114(3.1)$ & $6(0.5)$ & $38(3.4)$ & $280(4.3)$ & $10(3.6)$ & $54(20.0)$ \\
\hline Diarrhoea & & $\S$ & & & & ๆ \\
\hline Absence & 35368 (98.1) & $191(0.5)$ & $1657(4.7)$ & 6327 (97.4) & $294(4.7)$ & $1616(26.8)$ \\
\hline Presence & $691(1.9)$ & $9(1.3)$ & $43(6.3)$ & $168(2.6)$ & $5(3.0)$ & $23(14.1)$ \\
\hline Rectal bleeding & & ๆ & १ & & П & \\
\hline Absence & 33603 (93.2) & $153(0.5)$ & $1520(4.5)$ & 5297 (81.6) & $216(4.1)$ & $1370(27.0)$ \\
\hline Presence & $2456(6.8)$ & $47(1.9)$ & $180(7.5)$ & $1198(18.4)$ & $83(6.9)$ & 269 (24.1) \\
\hline Number of symptoms & & ף, $†$ & $\S, \dagger$ & & १, † & १, † \\
\hline No symptom & 28723 (79.7) & $120(0.4)$ & $1301(4.6)$ & $4322(66.5)$ & $167(3.9)$ & $1175(28.3)$ \\
\hline Any symptom & $7336(20.3)$ & $80(1.1)$ & $399(5.4)$ & 2173 (33.5) & $132(6.1)$ & $464(21.4)$ \\
\hline 1 & $5388(14.9)$ & $55(1.0)$ & $301(5.6)$ & 1599 (24.6) & $91(5.7)$ & $359(23.8)$ \\
\hline 2 & 1403 (3.9) & $17(1.2)$ & $75(5.4)$ & $445(6.9)$ & $32(7.2)$ & $79(19.1)$ \\
\hline $3+$ & $545(1.5)$ & $8(1.5)$ & $23(4.3)$ & $129(2.0)$ & $9(7.0)$ & $26(21.7)$ \\
\hline
\end{tabular}

*Individuals with colorectal adenocarcinoma were excluded from this analysis.

†Trend test.

$\neq \mathrm{p}<0.001, \mathrm{p} \geq 0.001$

$\S p \geq 0.01$ and $<0.05$

१P $<0.001$.

$\mathrm{CRC}$, colorectal cancer; FIT, faecal immunochemical test.

In addition, 501 individuals reported alternating bowel symptoms and/or general symptoms and/or other symptoms $(7.7 \%)$.

CRC was detected in $299(4.6 \%)$ individuals and advanced adenoma in 1639 (25.2\%); of whom 167 (55.9\%) individuals with CRC and 1175 (71.7\%) with advanced adenoma were asymptomatic.

Unadjusted analyses showed an association between abdominal pain, change in bowel habits, rectal bleeding and the detection of CRC (table 2). Multivariable analyses confirmed these results (ORs 1.8, 95\% CI 1.2 to 2.7; ORs 2.2; $95 \%$ CI 1.4 to 3.5 and ORs $1.8,95 \%$ CI 1.4 to 2.3 , respectively; figure 2$)$. The same associations were observed in men (OR 2.3, 95\% CI 1.3 to 4.1; ORs 2.8, $95 \%$ CI 1.5 to 5.0 ; ORs $2.0,95 \%$ CI 1.4 to 2.7 ), while in women only rectal bleeding was associated with the detection of CRC (OR 1.6, 95\% CI 1.0 to 2.4). The sensitivity of abdominal pain for CRC was $9.0 \%$, while it was $8.4 \%$ for change in bowel habits and $27.8 \%$ for rectal bleeding. The corresponding PPVs were $7.9 \%, 9.6 \%$ and $6.9 \%$, respectively (online supplemental table 3). Recent abdominal pain, change in bowel habits and rectal bleeding showed a higher OR than persistent symptoms compared with those not reporting these symptoms (OR 4.6, $95 \%$ CI 2.7 to 7.9 vs OR $0.7,95 \%$ CI 0.3 to 1.5 ; OR $2.3,95 \%$ CI 1.2 to 4.3 vs OR $1.5,95 \%$ CI 0.7 to 3.0 ; OR $2.8,95 \%$ CI 1.7 to 4.6 vs OR $1.7,95 \%$ CI 1.2 to 2.2 , respectively; online supplemental table 2). None of the symptoms were correlated with the detection of advanced adenoma. An increasing number of symptoms was correlated with the finding of 

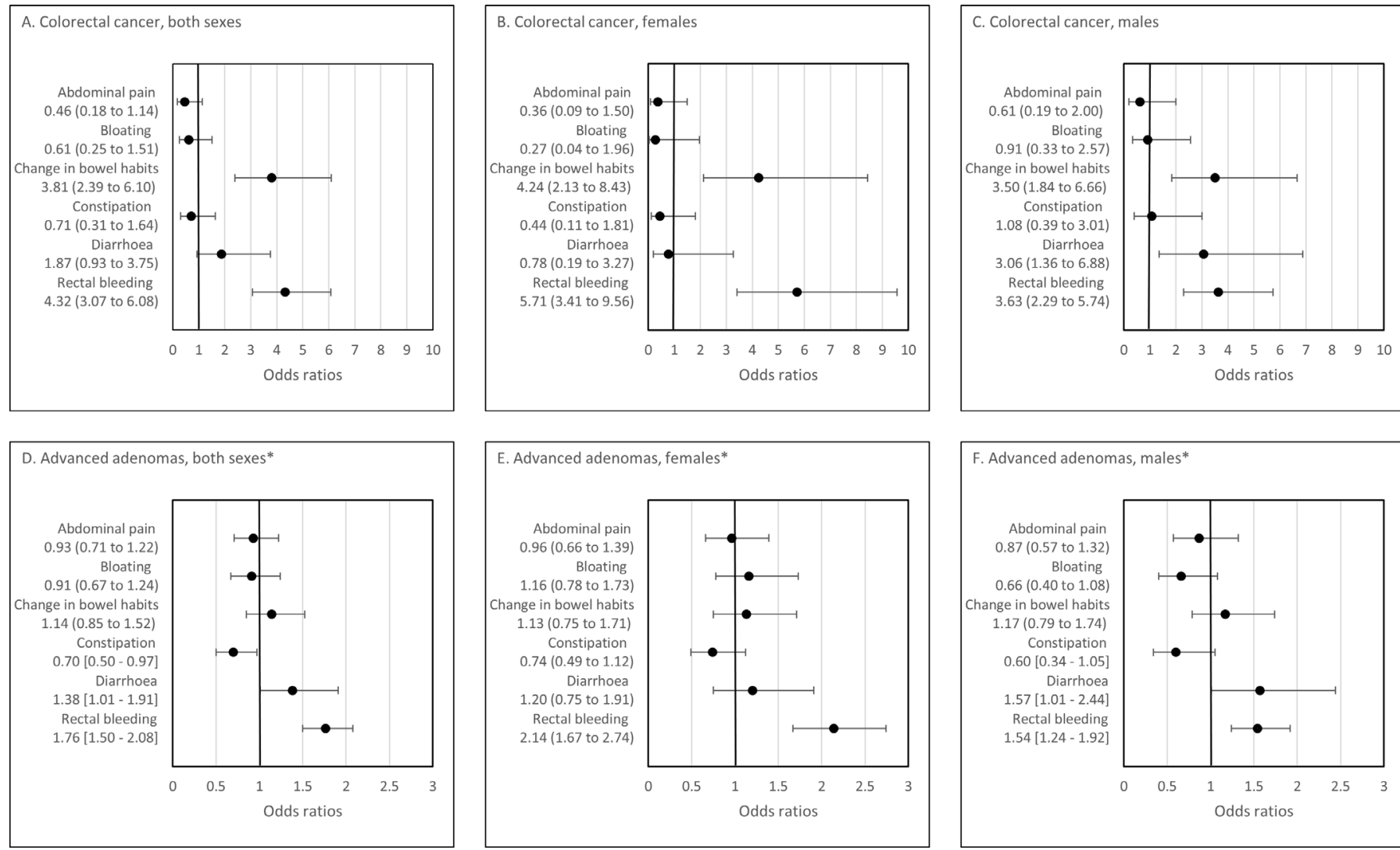

Figure 1 Association of bowel symptoms and detection of CRC/advanced adenoma in the sigmoidoscopy group (multivariable analysis). CRC, colorectal cancer.
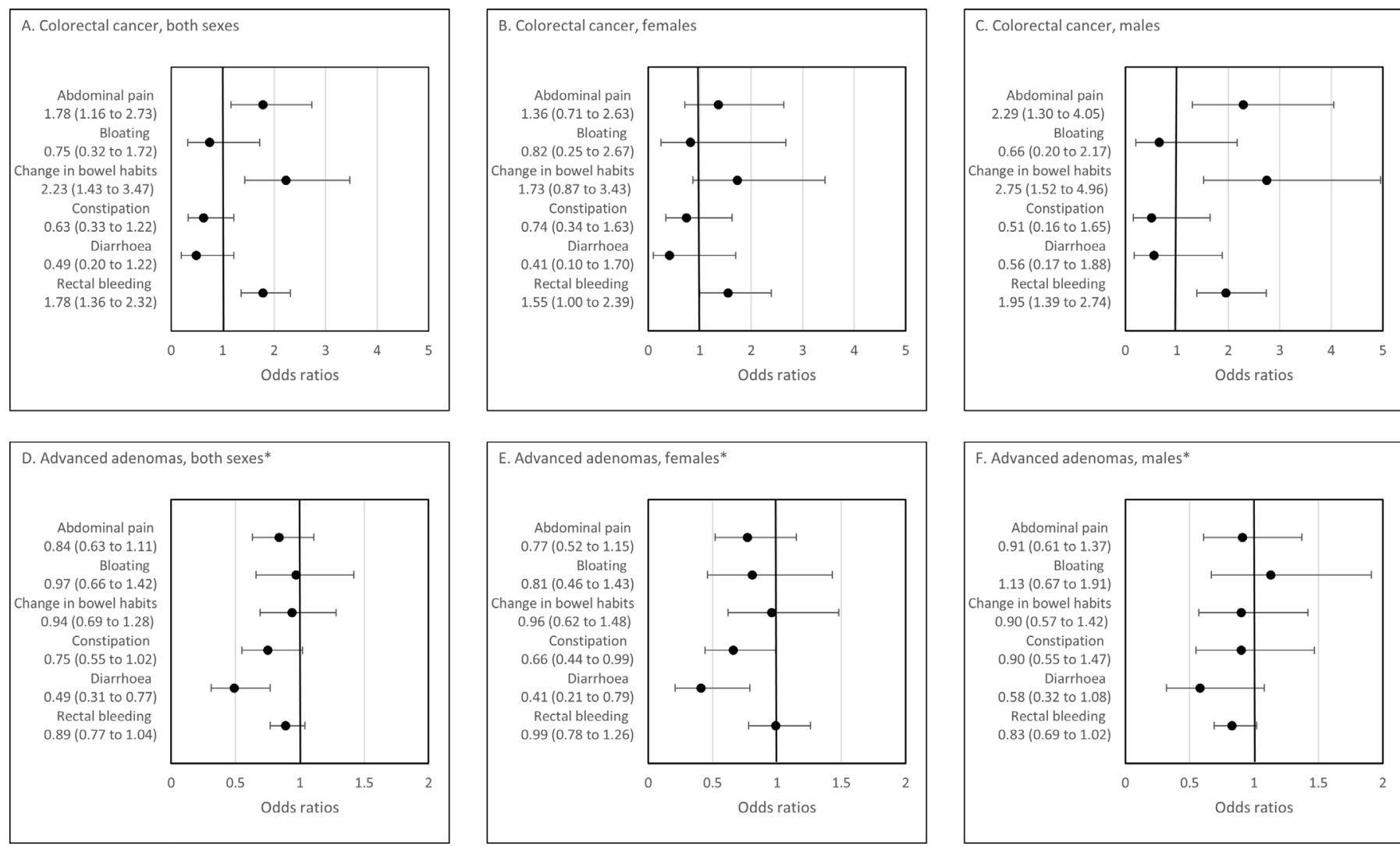

Figure 2 Association of bowel symptoms and detection of CRC/advanced adenoma in the FIT group (multivariable analysis). CRC, colorectal cancer; FIT, faecal immunochemical test. 
CRC at unadjusted (table 2) and multivariable analysis (OR 1.4, 95\% CI 1.2 to 1.6$)$.

\section{DISCUSSION}

To the best of our knowledge, this is so far the largest study assessing the proportion of asymptomatic patients diagnosed with CRC and advanced adenoma in a screening population. It shows that approximately six out of ten participants diagnosed with CRC were asymptomatic when sigmoidoscopy or FIT was the primary screening method. About three out of four diagnosed with advanced adenoma were asymptomatic. The study also demonstrates that more than one out of five attending sigmoidoscopy and one out of three with a positive FIT reported bowel symptoms. Rectal bleeding and change in bowel habits were associated with the detection of CRC regardless of the primary screening method. Abdominal pain was associated with CRC detection in FIT positive attenders and diarrhoea was associated with CRC detection in male sigmoidoscopy participants. Rectal bleeding and diarrhoea were associated with screen-detected advanced adenomas in attenders to sigmoidoscopy.

The results of our study are in line with previous much smaller studies showing that the majority of screen-detected CRCs are found in asymptomatic participants. ${ }^{17} 1821$ Still, asymptomatic persons may be more reluctant to attend screening programmes than persons having bowel symptoms. For individual decision-making, it is understandable that bowel symptoms reduce the barrier to attend screening. However, this may cause a general misconception that CRC screening is for those presenting bowel symptoms. ${ }^{1112}$

Based on reasons for willingness to attend CRC screening, one may assume that the prevalence of bowel symptoms is higher in screening participants than in the general population. ${ }^{12} 15$ A current population-based survey stated that more than one in four adults in the general population meet the Rome IV criteria for functional bowel disorders. ${ }^{26}$ The same frequency of bowel symptoms was found in a previous Norwegian survey. ${ }^{27}$ In general, surveys may be prone to self-selection bias and another limitation is that no endoscopic examination was performed. However, most studies of bowel symptoms in screening cohorts involving examination of the colon report even higher prevalence of bowel symptoms. These studies are performed in FOBT positive screening cohorts with an increased awareness of symptoms and a higher probability of neoplastic findings. ${ }^{1920}$ The participants in the present study reported considerably less symptoms than shown in these publications. One possible explanation may be less selection bias due to inclusion without preconsent and a relatively high participation rate of $52 \%$ in sigmoidoscopy screening, and $68 \%$ in FIT. ${ }^{24}$ The frequency of bowel symptoms is in line with the abovementioned surveys on functional bowel symptoms in the general population.
In attenders to sigmoidoscopy, rectal bleeding, the most common symptom, was strongly associated with the detection of CRC. Nevertheless, the PPV for rectal bleeding was only $1.9 \%$, that is, $98.1 \%$ of those with rectal bleeding were not diagnosed with CRC and we emphasise that 120 of 200 screening detected CRC were found in asymptomatic individuals. We also observed an association between rectal bleeding and advanced adenomas as well as diarrhoea in men and advanced adenomas in attenders to sigmoidoscopy. The detection and removal of precancerous lesions is crucial to prevent malignancy and one of the main goals of CRC screening. However, since the majority (1301 of 1700) of advanced adenomas were found in asymptomatic screening participants, bowel symptoms had very limited relevance as predictors of advanced adenoma. Our findings are in line with the Italian sigmoidoscopy screening programme, reporting that rectal bleeding and the combination of rectal bleeding and change in bowel habits were associated with the detection of both distal CRC and distal adenomas $>1 \mathrm{~cm} .{ }^{17}$ However, in this study, only $4 \%$ of the initially contacted individuals participated. ${ }^{17}$ Therefore, a higher risk of selection bias can be assumed compared with the present study.

In FOBT screening populations, the association between bowel symptoms and the detection of CRC or advanced adenomas is conflicting. ${ }^{17-21}$ In FIT positive attenders, change in bowel habits had the strongest association with detection of CRC. However, the sensitivity was low, indicating that only a minority of individuals with CRC would be identified by change in bowel habits. The highest sensitivity $(27.8 \%)$ was observed for rectal bleeding but at a low specificity $(82 \%)$. This implies that almost one out of five not detected with CRC would report rectal bleeding, while still only every fourth case of CRC would be identified by a history of rectal bleeding. A similar association between change in bowel habit and rectal bleeding with CRC was observed in the Dutch screening programme ${ }^{18}$ while no association was found between symptoms and findings in the English and Scottish guaiac based FOBT screening programme. ${ }^{19-21}$ Better sensitivity and specificity of FIT compared with guaiac based FOBT may be one reason for this difference. Abdominal pain predicted CRC in attenders with a positive FIT, but not in sigmoidoscopy participants. A difference in cancer stage or proportion of stricturing CRC could have been an explanation, but there was no such difference (data not shown). We also found, like in Funchs retrospective study, that CRC patients tended to report symptoms of short duration. ${ }^{28}$ Again, we want to emphasise that also in FIT screening, the majority, 167 of 299 individuals diagnosed with CRC, were asymptomatic. In line with previous FOBT screening studies, there was no association between symptoms and the detection of advanced adenomas. ${ }^{18-21}$

In both sigmoidoscopy participants and FIT positive attenders, there was a male predominance regarding the association between bowel symptoms and the detection of CRC and advanced adenomas. One possible reason may 
be that women suffer more frequently from irritable bowel syndrome, ${ }^{29}$ characterised by abdominal pain, bloating, change in bowel habits, constipation and diarrhoea.

CRC screening intends to be a healthcare service for asymptomatic persons at average risk of developing CRC. Nevertheless, a substantial proportion of screening participants presented symptoms associated with the finding of CRC and advanced adenomas. This indicates that screening may serve as a reminder to seek advice for bowel symptoms.

The validity of the results of our study is supported by its size, high participation rate and prospective recording of symptoms. Nevertheless, a limitation is that only $9 \%$ of the participants in the sigmoidoscopy group wereaccording to the protocol-examined with colonoscopy. Therefore, we may have missed some CRCs and advanced adenomas in the proximal colon. Attenders with a positive FIT have a higher probability for neoplasia than the general population. They also may have an increased awareness of bowel symptoms. Sigmoidoscopy participants may be more comparable to the general population. Still, it is known that there are barriers and facilitators to CRC screening participation, regardless of the screening modality. ${ }^{30}$ Therefore, both populations are at high risk for selection bias and the results may not be generalisable to the general public, but may be transferred to other comparable screening populations.

\section{CONCLUSION}

Most CRCs and advanced adenomas were found in asymptomatic participants. In the absence of symptoms, individuals at average risk for CRC in the age group 50-74 years should be encouraged to adhere to screening programmes.

Rectal bleeding and change in bowel habits were associated with detection of CRC.

\section{Author affiliations \\ ${ }^{1}$ Section for Colorectal Cancer Screening, Cancer Registry of Norway, Oslo, Norway ${ }^{2}$ Institute of Clinical Medicine, University of Oslo, Oslo, Norway \\ ${ }^{3}$ Department of Medicine, Vestre Viken Hospital Trust Bærum, Gjettum, Norway \\ ${ }^{4}$ Research Department, Cancer Registry of Norway, Oslo, Norway \\ ${ }^{5}$ Department of Research and Development, Telemark Hospital Trust, Skien, Norway \\ ${ }^{6}$ Institute of Health and Society, University of Oslo, Oslo, Norway \\ ${ }^{7}$ Department of Medicine, Østfold Hospital Trust, Grålum, Norway \\ ${ }^{8}$ Department of Medicine, Sørlandet Hospital Trust Kristiansand, Kristiansand, \\ Norway \\ ${ }^{9}$ Department of Molecular and Clinical Medicine, Sahlgrenska Academy, University of Gothenburg, Gothenburg, Sweden \\ ${ }^{10}$ Department of Medicine, Sahlgrenska University Hospital - Mölndal, Mölndal, Region Västra Götaland, Sweden \\ ${ }^{11}$ Department of Medical Research, Vestre Viken Hospital Trust Bærum, Gjettum, Norway}

Acknowledgements We would like to thank the devoted secretaries, nurses and doctors at Bærum and Moss hospital and bioengineers at Oslo University Hospital as well as the user representative in the Norwegian bowel cancer screening trial's steering committee for their much valued contribution.

Contributors Study concept and design: ALS, TdL, GH and $\emptyset$ H. Acquisition, analysis or interpretation of data: ALS, EB, GH, KRR, ED, SLE, ØH and TdL. Drafting of the manuscript: ALS, EB, GH, ØH and TdL. Critical revision of the manuscript for important intellectual content: ALS, EB, GH, KRR, ED, SLE, ØH and TdL. Statistical analysis: ALS and EB. All authors approved the final report and are accountable for all aspects of this work. All authors had full access to all of the data (including statistical reports and tables) in the study and take responsibility for the integrity of the data and the accuracy of the data analysis.

Funding This work was supported by the Norwegian Parliament (Norwegian national budget from 2011), grant number not applicable, in preparation for a future nation-wide colorectal cancer screening programme. The funders of the study had no role in study design, data collection, data analysis, data interpretation or writing of the report.

Competing interests All authors have completed the ICMJE uniform disclosure form at www.icmje.org/coi_disclosure.pdf and declare: KRR is supported by a research grant from the South-Eastern Norway Regional Health Authority (grant number 2015038); the remaining authors disclose no relationships or activities that could appear to have influenced the submitted work. The bowel preparation used for colonoscopy was provided free of charge by Ferring Pharmaceuticals.

Patient consent for publication Not required.

Ethics approval The trial was approved by the Regional Committee for Medical Research Ethics in South East Norway (2011/1272).

Provenance and peer review Not commissioned; externally peer reviewed.

Data availability statement Data are available upon reasonable request. Deidentified individual data may be available after the main follow-up data from the Norwegian bowel screening trial has been published. Data will be shared with investigators whose proposed use of the data has been approved by the Bowel cancer screening in Norway steering committee.

Supplemental material This content has been supplied by the author(s). It has not been vetted by BMJ Publishing Group Limited (BMJ) and may not have been peer-reviewed. Any opinions or recommendations discussed are solely those of the author(s) and are not endorsed by BMJ. BMJ disclaims all liability and responsibility arising from any reliance placed on the content. Where the content includes any translated material, BMJ does not warrant the accuracy and reliability of the translations (including but not limited to local regulations, clinical guidelines, terminology, drug names and drug dosages), and is not responsible for any error and/or omissions arising from translation and adaptation or otherwise.

Open access This is an open access article distributed in accordance with the Creative Commons Attribution Non Commercial (CC BY-NC 4.0) license, which permits others to distribute, remix, adapt, build upon this work non-commercially, and license their derivative works on different terms, provided the original work is properly cited, appropriate credit is given, any changes made indicated, and the use is non-commercial. See: http://creativecommons.org/licenses/by-nc/4.0/.

ORCID iDs

Anna Lisa Schult http://orcid.org/0000-0002-5773-1504

Thomas de Lange http://orcid.org/0000-0003-3989-7487

\section{REFERENCES}

1 Bray F, Ferlay J, Soerjomataram I, et al. Global cancer statistics 2018: GLOBOCAN estimates of incidence and mortality worldwide for 36 cancers in 185 countries. CA Cancer J Clin 2018;68:394-424.

2 Kuipers EJ, Grady WM, Lieberman D, et al. Colorectal cancer. Nat Rev Dis Primers 2015;1:15065.

3 Astin M, Griffin T, Neal RD, et al. The diagnostic value of symptoms for colorectal cancer in primary care: a systematic review. Br J Gen Pract 2011;61:e231-43.

4 Ford AC, Veldhuyzen van Zanten SJO, Rodgers CC, et al. Diagnostic utility of alarm features for colorectal cancer: systematic review and meta-analysis. Gut 2008;57:1545-53.

5 Jellema P, van der Windt DAWM, Bruinvels DJ, et al. Value of symptoms and additional diagnostic tests for colorectal cancer in primary care: systematic review and meta-analysis. BMJ 2010;340:c1269.

6 Howlader NNA, Krapcho M, Miller D, et al. Seer cancer statistics review, 1975-2016, National cancer Institute. Bethesda, MD 2019, 2019. Available: https://seer.cancer.gov/csr/1975_2016/

7 Brenner H, Hoffmeister M, Stegmaier C, et al. Risk of progression of advanced adenomas to colorectal cancer by age and sex: estimates based on 840,149 screening colonoscopies. Gut 2007;56:1585-9. 
8 Holme Øyvind, Schoen RE, Senore C, et al. Effectiveness of flexible sigmoidoscopy screening in men and women and different age groups: pooled analysis of randomised trials. BMJ 2017;356:i6673.

9 Holme Øyvind, Bretthauer M, Fretheim A, et al. Flexible sigmoidoscopy versus faecal occult blood testing for colorectal cancer screening in asymptomatic individuals. Cochrane Database Syst Rev 2013;9:CD009259.

10 Tinmouth J, Lansdorp-Vogelaar I, Allison JE. Faecal immunochemical tests versus guaiac faecal occult blood tests: what clinicians and colorectal cancer screening programme organisers need to know. Gut 2015;64:1327-37.

11 Denters MJ, Bossuyt PM, Deutekom M, et al. Most participate in faecal immunochemical test-based colorectal cancer screening out of curiosity about their chances of developing cancer. Eur $J$ Cancer Prev 2015:24:176-9.

12 de Wijkerslooth TR, de Haan MC, Stoop EM, et al. Reasons for participation and Nonparticipation in colorectal cancer screening: a randomized trial of colonoscopy and CT colonography. Am J Gastroenterol 2012;107:1777-83.

13 Jones RM, Woolf $\mathrm{SH}$, Cunningham TD, et al. The relative importance of patient-reported barriers to colorectal cancer screening. Am J Prev Med 2010;38:499-507.

14 McLachlan S-A, Clements A, Austoker J. Patients' experiences and reported barriers to colonoscopy in the screening context--a systematic review of the literature. Patient Educ Couns 2012;86:137-46.

15 Taskila T, Wilson S, Damery S, et al. Factors affecting attitudes toward colorectal cancer screening in the primary care population. $\mathrm{Br}$ $J$ Cancer 2009;101:250-5.

16 Subramanian S, Klosterman M, Amonkar MM, et al. Adherence with colorectal cancer screening guidelines: a review. Prev Med 2004;38:536-50.

17 Ferraris R, Senore C, Fracchia M, et al. Predictive value of rectal bleeding for distal colonic neoplastic lesions in a screened population. Eur J Cancer 2004;40:245-52.

18 de Klerk CM, van der Vlugt M, Bossuyt PM, et al. A large proportion of fecal immunochemical test-positive participants in colorectal cancer screening is symptomatic. United European Gastroenterol J 2018;6:471-9.
19 Rajasekhar PT, Ritchie M, Rutter MD, et al. Lower gastrointestinal symptoms are prevalent among individuals colonoscoped within the bowel cancer screening programme. Colorectal Dis 2012;14:e603-7.

20 Ahmed S, Leslie A, Thaha MA, et al. Lower gastrointestinal symptoms are not predictive of colorectal neoplasia in a faecal occult blood screen-positive population. Br J Surg 2005;92:478-81.

21 Saldanha JD, Moug SJ, Linton K, et al. Symptoms do not predict colorectal cancer in an Fob screened population. Scott Med J 2013;58:95-8.

22 Adelstein B-A, Macaskill P, Chan SF, et al. Most bowel cancer symptoms do not indicate colorectal cancer and polyps: a systematic review. BMC Gastroenterol 2011;11:65.

23 Olde Bekkink M, McCowan C, Falk GA, et al. Diagnostic accuracy systematic review of rectal bleeding in combination with other symptoms, signs and tests in relation to colorectal cancer. $\mathrm{Br} J$ Cancer 2010;102:48-58.

24 Randel KR, Schult AL, Botteri E, et al. Colorectal cancer screening with repeated fecal immunochemical test versus sigmoidoscopy: baseline results from a randomized trial. Gastroenterology 2021;160:1085-96.

25 Cuzick J. A wilcoxon-type test for trend. Stat Med 1985;4:87-90.

26 Palsson OS, Whitehead W, Törnblom H, et al. Prevalence of Rome IV functional bowel disorders among adults in the United States, Canada, and the United Kingdom. Gastroenterology 2020;158:1262-73.

27 Breckan RK, Asfeldt AM, Straume B, et al. Prevalence, comorbidity, and risk factors for functional bowel symptoms: a population-based survey in northern Norway. Scand J Gastroenterol 2012;47:1274-82.

28 Funch DP. Predictors and consequences of symptom reporting behaviors in colorectal cancer patients. Med Care 1988;26:1000-8.

29 Houghton LA, Heitkemper M, Crowell MD, et al. Age, gender, and women's health and the patient. Gastroenterology 2016;150:1332-43.

30 Wools A, Dapper EA, de Leeuw JRJ. Colorectal cancer screening participation: a systematic review. Eur J Public Health 2016;26:158-68. 